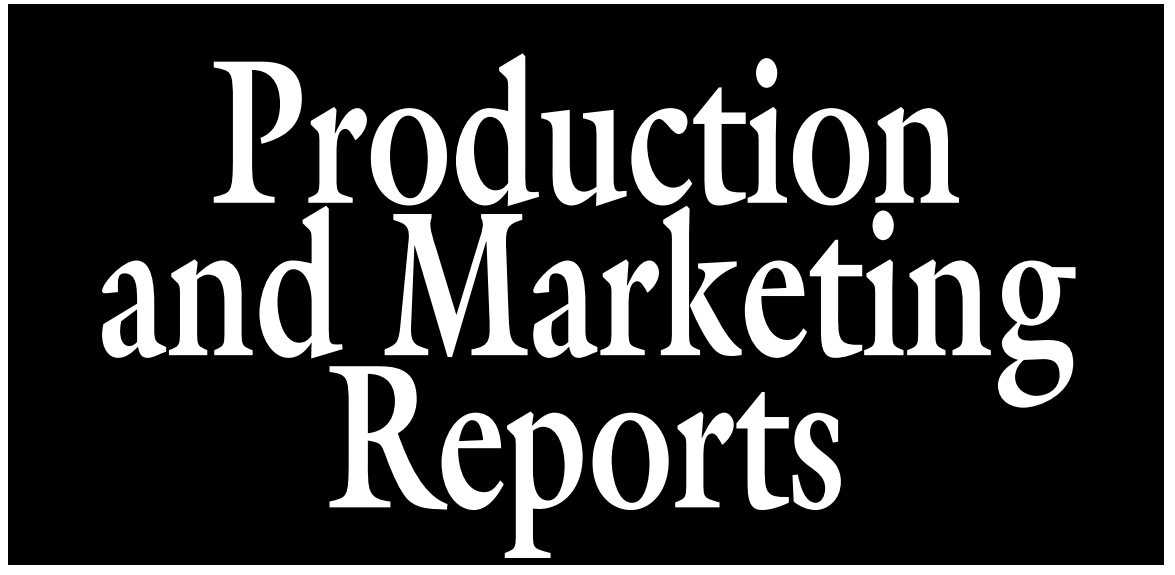

\section{An Econometric Demand Model for Florida Green-skin Avocados}

\author{
Edward A. Evans ${ }^{1}$ and Fredy H. Ballen
}

ADDITIONAL INDEX WORDs. inverse demand, price elasticity, price flexibility, cross price elasticity, Xlyleborus glabratus, Raffaelea lauvicola, Persea americana

SuMmARY. This article develops an inverse demand model for Florida green-skin avocados (Persea americana). Information from the model is used to assess the likely impact on growers' prices resulting from a reduction in the supply of Florida greenskin avocados due to a recent outbreak of a deadly fungus in the Florida commercial avocado production area. Consideration is also given to the increased supply of green-skin avocados imported to the United States from the Dominican Republic (DR), as well as the increased availability of 'Hass' avocado in the U.S. market. The estimated own price flexibility of $-\mathbf{0 . 5 5 1}$ evaluated at the mean suggests that Florida avocado prices are not very responsive to changes in quantity supplied. A reduction in the quantity supplied is likely to bring about a less than proportionate rise in the price. Moreover, any noticeable rise in prices due to the impact of the disease is likely to be short lived and may be insufficient to cover additional grove management costs. In the longer run, prices are expected to revert closer to their long-run trend (or decrease) as a result of increased shipments from the DR, and further increases in the availability of 'Hass' avocados.

$\mathrm{T}$ he United States is one of the world's major producers and leading importers of avocados, ranking fourth in the global production of avocados in 2012, with an annual crop volume of around 245,000 t $[270,066.3$ tons (Food and Agriculture Organization of the United Nations, 2014)]. The bulk (88.04\%) of U.S. avocado production is of the cultivar Hass, with the balance being classified as a "green-skin" cultivar. U.S. production of 'Hass' avocado occurs predominately in California while production of the green-skin cultivar occurs mainly in Florida [California Avocado Commission, 2014; U.S. Department

University of Florida, Tropical Research and Education Center, 18905 SW 280th Street, Homestead, FI 33031

${ }^{1}$ Corresponding author. E-mail address: eaevans@ufl. edu. of Agriculture (USDA), Economic Research Service (ERS), 2014a]. The United States is among the top global importers of avocado, importing in excess of $571,000 \mathrm{t}(629,419.8$ tons $)$, valued at $\approx \$ 1.09$ billion in 2013 [USDA, Foreign Agricultural Service (FAS), 2014]. 'Hass' comprises the bulk of avocado imports, accounting for more than $95.77 \%$ of the volume traded in 2013 , followed by greenskin avocados at $\approx 2.53 \%$ and organic 'Hass' at $1.70 \%$ (USDA-FAS, 2014).
Despite its relatively low importance in terms of U.S. domestic production and trade, and the undeniable increasing popularity of 'Hass' avocados, the green-skin avocado industry represents a very important component of the Florida agricultural economy. An example of this is the fact that annual farm gate sales were worth $\approx \$ 24.4$ million in 2013-14, with an overall economic impact of close to $\$ 100$ million per annum (A. Hodges, personal communication; USDA-ERS, 2014b). Contributing factors are that the green-skin cultivar is favored over 'Hass' by consumers with ties to the Caribbean and to Central and South America, and by consumers interested in a lower calorie-count.

Until recently, the U.S. greenskin avocado market has mainly been supplied by the domestic production coming from Florida, but now imports have begun to assume a greater level of importance in the market. The $\mathrm{DR}$ is emerging as the main overseas supplier of green-skin avocados to the United States, with imports from the DR almost doubling between 2004 and 2013 , increasing from 8477 to $14,397 \mathrm{t}[9344.3$ to $15,870.0$ tons (USDA-FAS, 2014)]. The DR now supplies $\approx 99.41 \%$ of the total U.S. green-skin avocado imports and accounts for roughly one-third of the total quantity of green-skin avocados consumed in the United States [USDA, Agricultural Marketing Service (AMS), 2014a; USDA-FAS, 2014]. It is apposite to note that the DR avocado industry, which is roughly four times the size of that of Florida, has the potential to further increase its market share in the industry.

Adding to the challenges of rising imports from the DR, the Florida avocado industry is under severe threat due to the arrival of an invasive pest (Xlyleborus glabratus) and its nutritional symbiont, a fungus identified as Raffaelea lauricola that causes the deadly disease known as

\begin{tabular}{llll}
\hline $\begin{array}{l}\text { Units } \\
\begin{array}{l}\text { To convert U.S. to SI, } \\
\text { multiply by }\end{array}\end{array}$ & U.S. unit & SI unit & $\begin{array}{l}\text { To convert SI to U.S., } \\
\text { multiply by }\end{array}$ \\
\hline 0.4047 & $\mathrm{acre}(\mathrm{s})$ & $\mathrm{ha}$ & 2.4711 \\
0.4536 & $\mathrm{lb}$ & $\mathrm{kg}$ & 2.2046 \\
28.3495 & $\mathrm{oz}$ & $\mathrm{g}$ & 0.0353 \\
0.9072 & $\mathrm{ton}(\mathrm{s})$ & $\mathrm{t}$ & 1.1023
\end{tabular}


laurel wilt disease, which was first discovered in the commercial avocado areas in Florida in 2012. The disease is so deadly that infected trees usually die within a matter of weeks (Evans et al., 2010). Although research is currently underway to identify the best means of combating the spread of the disease, a cost-effective treatment remains to be identified, although there are a few promising results. An area-wide management program centered on sanitation (early detection and removal of symptomatic trees), which was put into effect in 2012, has had only limited success in slowing the spread of the disease in the commercial avocado areas. Tree removal and the proper disposal and treatment of adjacent trees have increased orchard management costs by as much as $\$ 1000 /$ acre (E.A. Evans and F.H. Ballen, unpublished data). To date, $\approx 7000$ avocado trees, or $\approx 1 \%$ of the commercial avocado trees in Florida, have had to be eradicated. This is equivalent to a loss of $\approx 70$ acres, or 17,500 bushels (based on the assumption of an average yield of $\approx 250$ bushels per acre, where 1 bushel $=55 \mathrm{lb}$ ) since some of these orchards would be less than well maintained (Evans and Lozano, 2014).

With the looming threat to the industry, stemming both from increased foreign competition and the effects of the disease, there is an urgent need to characterize the market for green-skin avocados in the United States so that growers and industry operatives can become more fully aware of the price and revenue implications that could result from changes in domestic supply and/or increased overseas supplies of greenskin avocados from the DR. In particular, there is the need to estimate demand parameters, such as own and cross price elasticities and flexibilities, which could be used to further analyze potential price and revenue implications. Accordingly, the objective of this research is to estimate the demand for green-skin avocados in the United States and to use the findings to shed light on the possible price effects resulting from changes in the quantity supplied.

Our study represents a first attempt to provide an empirical model for the demand of Florida greenskin avocados, as most of the

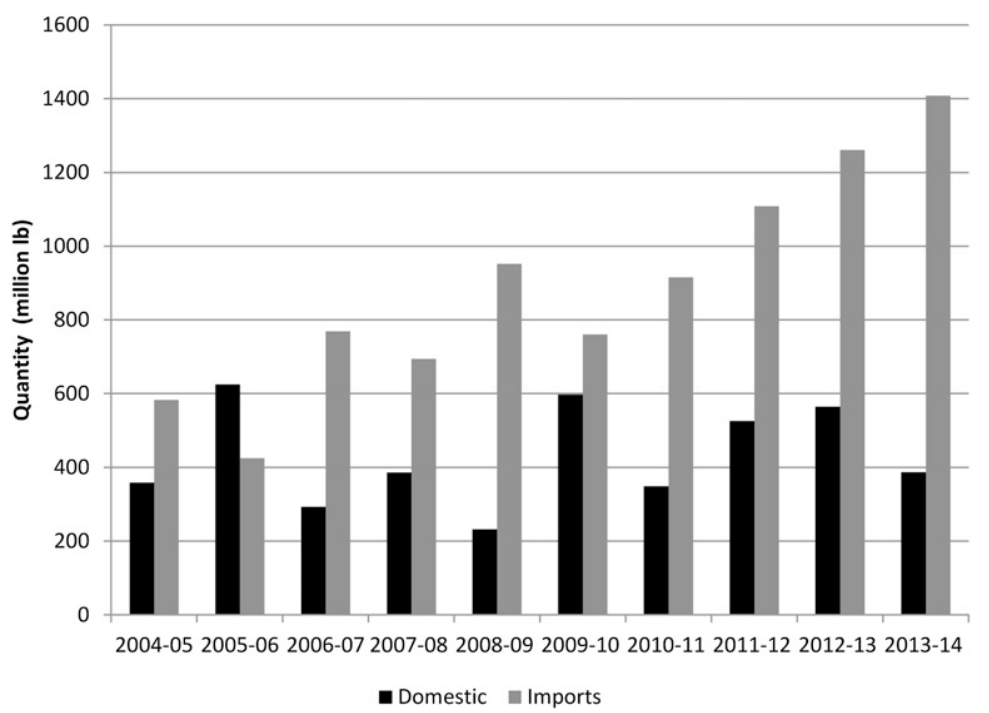

Fig. 1. U.S. supply of avocados comprising domestic avocado production sourced from California, FL, and Hawaii and total imports, for the period 2004-05 to 2013-14 (USDA-FAS, 2014); $1 \mathrm{lb}=0.4536 \mathrm{~kg}$.

literature has been focused on 'Hass' in the U.S. avocado industry. It also contributes to the literature on tropical fruit demand in the U.S. market. Results provide quantitative estimates, making it possible to assess the impacts of different policy and business decisions in the Florida avocado industry.

\section{U.S. avocado market}

U.S. avocado production occurs in California, Florida, and Hawaii. California is the main producer of avocados, accounting for $83.97 \%$ of the total production during crop year 2013-14, followed by Florida with $15.86 \%$ and Hawaii with $0.17 \%$ (USDA-ERS, 2014b). In terms of cultivars, California grows mainly 'Hass' while Florida grows the green-skin cultivars.

U.S. domestic avocado production and trade from 2004-05 to 2013-14 are depicted in Fig. 1. This figure shows that U.S. avocado production fluctuated from a low of 231.9 million pounds in $2008-09$ to a high of 624.8 million pounds in 2005-06, and the farm gate value of U.S. avocado production decreased $\approx 37 \%$ between $2010-11$ and 2013-14 (USDA-ERS, 2014a, 2014b). It is important to note that avocado yield is affected by both abiotic and biotic factors, since avocado trees have a tendency to exhibit an alternate bearing cycle, resulting in a large crop of small avocados 1 year, followed by a small crop of large avocados the next year.

In contrast to domestic production, U.S. consumption of avocados has been on the rise, with per capita avocado consumption increasing by $77.91 \%$, from $3.17 \mathrm{lb}$ in 2004 to $5.64 \mathrm{lb}$ in 2013 (USDA-ERS, 2014a). The noticeable rise in U.S. per capita consumption of avocados is due mainly to surging imports since domestic production has remained more or less the same over the last several years, save the year-to-year fluctuation. Figure 1 shows that between 2004-05 and 2013-14, U.S. avocado imports grew by $141.77 \%$, from 582.5 to 1408.3 million pounds (USDA-ERS, 2014a).

Since 2004, Mexico has emerged as the main U.S. fresh avocado overseas supplier, with a share of $72.39 \%$ of the total avocado imports in 2013, followed by Chile with $21.93 \%$, the DR with $4.24 \%$, and others with $1.44 \%$ (USDA-FAS, 2014). Almost all of the Mexican and Chilean fresh avocado exports to the United States correspond to the 'Hass' avocado, which has become popular for its buttery flavor and excellent shelf life. In contrast, DR fresh avocado exports to the United States are mainly green-skin avocado cultivars similar to those produced by Florida growers. U.S. green-skin avocado import volumes have increased, from $8729 \mathrm{t}$ (9622.1 tons) in 2004 to $14,482 \mathrm{t}$ $(15,963.7$ tons) in 2013 , or by $\approx 66 \%$ (USDA-FAS, 2014). Over the same 
period, the value of green-skin avocado imports has more than doubled, from $\$ 7.70$ million in 2004 to $\$ 15.59$ million in 2013 (USDA-FAS, 2014).

\section{Florida avocado industry and U.S. green-skin avocado market}

Ranking third after citrus (Citrus sp.) and blueberry (Vaccinium sp.), respectively (Florida Department of Agriculture and Consumer Services, 2013), avocados are a key component of the Florida tree fruit production; in terms of cash receipts, with annual farm gate sales reaching \$24.4 million in the 2013-14 season (USDA-ERS, 2014b). At the wholesale market level, the Florida avocado industry is worth upwards of $\$ 35$ million per year (P. Brooks, personal communication). About $80 \%$ of the crop is sold outside of the state; hence, the industry brings in a substantial amount of "new dollars" to Florida, resulting in an overall economic impact of $\$ 99.4$ million per annum (A. Hodges, personal communication). The Florida avocado industry consists of $\approx 7000$ acres, representing $\approx 60 \%$ of the total tropical-fruit crop acreage in the state. Over $98 \%$ of the green-skin avocado acreage is located in southwest Miami-Dade County. The range in orchard size is from 0.1 to over 500 acres. On average, $93 \%$ of the farms are 15 acres or less, and the most common farm size category is 1 to 5 acres [USDA, National Agricultural Statistics Service (NASS), 2014)] There are $\approx 500$ registered growers and $\approx 30$ registered avocado handlers and shippers in this area of the state (A. Flinn, personal communication).

Unlike California, where 'Hass' is the predominant cultivar grown, Florida commercially grows $\approx 60$ different green-skin avocado cultivars. Florida avocados are classified into three main groups: West Indian, Guatemalan, and Mexican "races". Maturity season varies according to the group/race, with the growing season lasting from about June to March. Fruit shape ranges from spherical to pyriform; the fruit weigh from a few ounces to $5 \mathrm{lb}$ each (Crane et al., 2013). The main nutritional difference between California and Florida avocados is fat content. For each golf-ball-sized portion, a California 'Hass' avocado contains $4.6 \mathrm{~g}$ of fat while the same portionsized Florida green-skin avocado averages $3 \mathrm{~g}$ of fat (American Institute of Cancer Research, 2013). Florida avocados may be appealing to the caloriesconscious consumer.

While Florida avocado production has fluctuated, from a low of 12,000 tons in the 2005-06 season to a high of 31,100 tons in the 201112 season (USDA-ERS, 2014b), the avocado production area remains about the same. The factors behind the observed yield fluctuation include abiotic and biotic factors, and the tendency of avocado trees to exhibit an alternate bearing pattern.

In contrast to the Florida avocado industry, DR avocado production has trended upward, from $218,790 \mathrm{t}(241,174.7$ tons $)$ in 2004 to $290,000 \mathrm{t}(319,670.3$ tons $)$ in 2012 , reaching a record high of $387,500 \mathrm{t}(427,145.6$ tons $)$ in 2013 (DR Ministry of Agriculture, 2014). With significant avocado production in the DR and the right price conditions in the U.S. market, DR avocado exporters may be able to react quickly to cover any shortage of Florida green-skin avocados.

In terms of imports, the DR is by far the predominant supplier of green-skin avocados to the U.S. market, with an average share in exports of $98.03 \%$ for $2010-13$, followed by Mexico with $0.87 \%$, Chile with $0.36 \%$, and others with $0.74 \%$ (USDA-FAS, 2014). It may be that the declining export pattern of green-skin avocados from Mexico and Chile to the United States is the result of a strategic decision to focus their production and export programs on the 'Hass'

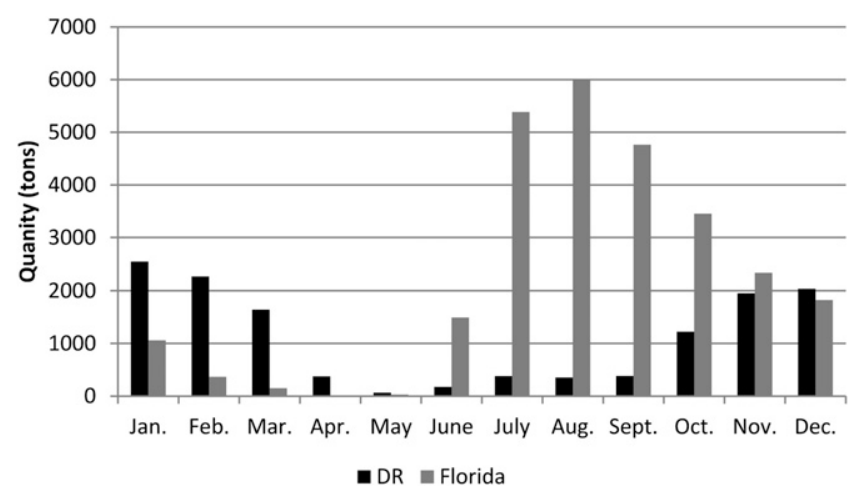

Fig. 2. The pattern of U.S. availability of green-skin avocados, shown on a monthly basis and by main suppliers, Florida and the Dominican Republic (DR), based on data for the period 2004-05 to 2013-14 (USDA-FAS, 2014); 1 ton $=0.9072 \mathrm{t}$. avocado, which is the predominant cultivar in the U.S. market.

Figure 2 depicts the monthly average green-skin avocado imports from the DR and U.S. domestic green-skin avocado production in Florida from 2004-05 to 2013-14. Because of differences in growing conditions in Florida and the DR, green-skin avocados are available year-round in the United States, although DR avocado supplies from April to September are relatively small. The bulk of the green-skin avocado season runs from June to December in Florida and from October to March in the DR (Fig. 2). Florida green-skin avocado growers enjoy a market advantage from June to November when they are the main source of the fruit in the market, while DR green-skin avocado growers have the advantage from December to March.

As an example of the difference in consumer preference, U.S. retail sales of 'Hass' avocados were $\approx \$ 1.4$ billion in 2012 while retail sales of green-skin avocados were $\approx \$ 69.9$ million. About $75 \%$ of the green-skin avocado retail sales in 2012 occurred on the U.S. east coast, specifically in the northeastern $(28 \%)$ and southeastern (47\%) regions (Hass Avocado Board, 2014).

\section{Conceptual framework}

Using the specifications of a traditional demand model, quantity becomes the dependent variable. Other approaches can also be used. One alternative approach to modeling a demand equation involves the estimation of an inverse demand model, which has become an accepted method 
in empirical work, especially in agricultural and natural resource markets, as supply conditions suggest that quantities are predetermined (Park and Thurman, 1999). Quantity may be considered predetermined in a demand model because of fixed biological lags in production (Thurman, 1987). In this case, price becomes the appropriate dependent variable, as it clears the market and absorbs current demand shocks for a non-storable fixed supply commodity.

A considerable research effort has been devoted to modeling U.S. 'Hass' avocado demand to evaluate the economic return/benefit of advertising and promotion activities. Domestic and imported 'Hass' avocados are subject to a levy assessment to finance generic advertising and promotion; therefore, periodic studies have been conducted to assess the effectiveness of the 'Hass' avocado promotion activities. The methodology often chosen in many studies involves the specification and estimation of an inverse demand model (Carman and Cook, 1996; Carman and Craft, 1998; Carman and Green, 1993).

The study by Carman and Craft (1998) examines the demand for California avocados, with emphasis on the impact of generic advertising and promotion using monthly data from 1986-87 to 1994-95. Because of heteroskedasticity and autocorrelation issues, the model is estimated using the instrumental variable generalized method of moments (IV/ GMM) method. In the estimated model, price for California avocados is specified as a function of sales of U.S. domestic avocados (California and Florida), sales of imported avocados, U.S. real disposable per capita income, advertising, and monthly dummy variables. The estimated price flexibilities (evaluated at the data means) are -1.54 for domestic avocados, and -0.25 for imported avocados. Monthly dummy variables significant at the $5 \%$ level or better include the months of December and the five months from May through September. The estimated price flexibility of advertising (0.137) also is significant.

Because of our interest in evaluating the impact of changes in the quantities of domestic and imported green-skin avocados and
'Hass' avocados on the prices of Florida avocados, we employ the inverse demand model.

\section{Empirical model and data}

The empirical specification of the model is as follows:

$$
\begin{aligned}
P_{\mathrm{FLGSt}}= & \beta_{0}+\beta_{1} Q G S_{\mathrm{FLt}}+\beta_{2} Q G S_{\mathrm{DRt}} \\
& +\beta_{3} Q H A S S t+\beta_{4} U S D P I t \\
& +\beta_{5} T+\sum_{i=1}^{9} \beta_{\mathrm{t}} D_{\mathrm{t}}+\varepsilon_{\mathrm{FLGSt}}
\end{aligned}
$$

where

$P_{\text {FLGSt }}$ : Price of Florida greenskin avocados at the wholesale level (dollars per kilogram)

$Q G S_{\mathrm{FLt}}$ : Monthly shipments of Florida avocado divided by U.S. population (grams per person)

$Q G S_{\mathrm{DRt}}$ : Monthly shipments of DR avocado divided by U.S. population (grams per person)

QHASSt: Monthly shipments of total 'Hass' divided by U.S. population (grams per person)

USDPIt: U.S. per capita disposable personal income (dollars)

T: Time trend

$D_{\mathrm{t}}$ : Monthly dummy variable, value is 1 if month is from July to March, and 0 otherwise

$\varepsilon_{\mathrm{FLGSt}}$ : Error term

The empirical model uses monthly data for the 10-year period from Jan. 2004 to Dec. 2013. Florida green-skin avocado is marketed from June to March (because of this, we exclude the months of April and May from the analysis). Therefore, the monthly dummy variables include the months from July to March, with June being the de facto base month.

Data for the model were obtained from several sources. Florida greenskin avocado prices, which represent the U.S. average price (dollars per kilogram) for Florida avocados at the terminal market, were calculated using data retrieved from USDA-AMS (2014b). Florida green-skin avocado shipment reports from USDA-AMS (2014a) were used to obtain data about the monthly production of Florida green-skin avocado. DR greenskin avocado quantity in the market consisted of monthly imports of the fruit (USDA-FAS, 2014). Data on the monthly quantity of total 'Hass' avocados in the U.S. market were comprised from total domestic production (California Avocado Commission,
2014) and total quantity imported (USDA-FAS, 2014). The U.S. per capita disposable personal income came from the U.S. Bureau of Economic Analysis (2014). Nominal prices and income were converted to real terms by deflating them with the U.S. consumer price index (U.S. Bureau of Economic Analysis, 2014).

To address potential simultaneity issues, IV estimation methods were selected to conduct the empirical estimation. To identify a demand equation, potential instruments included factors that shift the supply equation, such as input costs and producer expectations among others. Reliable data series representing Florida avocado production costs were unavailable, so the instruments selected in the present study were based on producer price expectations. Quantity of Florida green-skin avocado $Q F L_{\mathrm{GSt}}$ was instrumented with Producer Price Index for other fresh fruits (U.S. Bureau of Labor Statistics, 2014) and average monthly import prices for green-skin avocados from the DR (USDA-AMS, $2014 \mathrm{~b}$ ). These instruments were chosen, given that prices signal market conditions and growers have some flexibility in the timing for avocado harvest.

Preliminary estimation results using two-stage least squares (2SLS) found heteroskedasticity issues; therefore, the final model was estimated using the IV/GMM method with robust standard errors (Stata ivreg2 routine). The IV/GMM estimation method with robust standard errors to address heteroskedasticity was used by several authors in applied work to estimate demand models (Carman and Craft, 1998; Di Giacomo, 2008; Lee and Thunberg, 2013; Lundberg and Lundberg, 2012).

\section{Results and discussion}

Estimation results for the empirical model are presented in Table 1. Diagnostic tests show that autocorrelation is not an issue with the estimated model. Likewise, the results of the Hansen J-test indicate that overidentification is not a problem. The KleibergenPaap underidentification test which is used to determine whether the instruments are relevant shows that the model is identified. The coefficient of determination indicates that the estimated model explains $\approx 84 \%$ of the Florida green-skin 
Table 1. Florida green-skin avocado demand model prediction estimates with their coefficients, SE, obtained from regression analysis using instrumental variable generalized method of moments (IV/GMM) technique. Variables included are per capita monthly quantity of Florida green-skin avocados shipped, per capita mo.ly green-skin avocados imported from Dominican Republic, per capita monthly shipment of 'Hass' avocados (domestic and imported), U.S. per capita disposable income, time trend, and monthly dummy variables. The model uses monthly data for the 10-year period from Jan. 2004 to Dec. 2013.

\begin{tabular}{|c|c|c|}
\hline & \multicolumn{2}{|c|}{ IV/GMM } \\
\hline & Coefficient & Robust SE \\
\hline Intercept & -0.3902 & 0.9682 \\
\hline$Q G S_{\mathrm{FL}}$ & $-0.0130 * * *$ & 0.0032 \\
\hline$\widetilde{Q} G S_{\mathrm{DR}}$ & -0.0068 & 0.0047 \\
\hline$\widetilde{Q H A S S}$ & $-0.0002 * *$ & 0.0001 \\
\hline USDPI & 0.0015 & 0.0006 \\
\hline$T$ & $0.0028^{*}$ & 0.0017 \\
\hline July & 0.2582 & 0.1982 \\
\hline August & 0.2482 & 0.2271 \\
\hline September & 0.0456 & 0.1680 \\
\hline October & -0.7474 & 0.1601 \\
\hline November & -0.2562 & 0.1611 \\
\hline December & -0.3472 ** & 0.1518 \\
\hline January & -0.2383 & 0.1535 \\
\hline February & $-0.4707 * * *$ & 0.1148 \\
\hline March & $-0.5399 * * *$ & 0.1006 \\
\hline Hansen J stat ${ }^{\mathrm{z}}$ & $(0.937)$ & - \\
\hline Kleibergen-Paap & - & - \\
\hline Lagrange multiplier stat ${ }^{z}$ & $(0.003)$ & - \\
\hline Cumby-Huizinga $^{z}$ & $(0.500)$ & - \\
\hline Coefficient of determination & 0.83 & - \\
\hline
\end{tabular}

${ }^{\mathrm{z}} \chi^{2}$ probability values.

${ }^{* * *}$ Significant at the $1 \%$ level, ${ }^{* *}$ significant at the $5 \%$ level, ${ }^{*}$ significant at the $10 \%$ level.

avocado price variation at the wholesale level. Additionally, the results of the Ramsey/Pesaran-Taylor reset test indicate that the true relationship among the variables is linear.

The estimated parameter for the own price flexibility for Florida greenskin avocados evaluated at the data mean is -0.551 ; it has the expected negative sign and is statistically significant at the $1 \%$ level. The own price flexibility measures the percentage change in price resulting from a particular change in quantity. A direct marketing implication is that changes in quantity are not proportional to changes in prices, which are found to be affected considerably less. Given that the absolute value of the coefficient for the own price flexibility is less than 1 , it indicates a price inflexible demand for Florida greenskin avocados, which is consistent with an elastic demand.

The estimated parameter for the cross price flexibility of Florida avocados with respect to quantity of DR green-skin avocados has the expected negative sign, indicating a substitution relationship between the two avocado types, but it is not statistically significant. Results suggest that imports of DR green-skin avocado to the U.S. market do not have a significant effect on the pricing of Florida avocados. This may be explained by the lack of market competition because the bulk of the Florida avocado crop has been harvested and marketed by the time DR green-skin avocados arrive on the U.S. market.

The estimated cross price flexibility of Florida green-skin avocados with respect to 'Hass' avocado evaluated at the mean is -0.214 ; its negative sign indicates a substitution relationship, that is statistically significant at the 5\% level. Our findings are consistent with the study by Carman and Green (1993) that California avocados are a substitute for Florida avocados. A $10 \%$ increase in the quantity of 'Hass' avocado is associated with a $2.14 \%$ decrease in the price for Florida green-skin avocados. Any increases in the supply of domestic and imported 'Hass' avocados have a detrimental effect on the price for Florida avocados.

The income flexibility coefficient evaluated at the mean is 2.29 . It has the expected positive sign and indicates that Florida avocados are considered normal goods. A $1 \%$ increase in disposable personal income will increase the demand for Florida avocados by $2.29 \%$.

The model specification includes a time trend that is reasonable given the increase in the supply of imported green-skin avocado. The estimated coefficient indicates a positive relationship with Florida avocados and is significant at the $10 \%$ level.

The monthly dummy variables take into consideration seasonal changes in demand after accounting for seasonal patterns in production and imports. The estimated coefficients measure real price differences for the first month of the marketing year (June). The coefficients that are statistically significant at the $5 \%$ or better level include the months of December, February, and March, indicating that real prices of Florida green-skin avocados are, respectively, $\$ 0.35, \$ 0.48$, and $\$ 0.55$ per kilogram lower compared with the base month of June. Demand for Florida avocados is at its seasonal low in March.

Most empirical demand studies focus on the estimation of price elasticities; studies estimating direct price flexibilities are scarce and the situation is even more critical in the context of demand for fruits. Our estimated direct price flexibility for Florida green-skin avocados is close in range with previous own price flexibility estimates for fruit such as apples [Malus $\times$ domestica $(-0.413)]$, grapes [Vitis sp. (-0.419)], and bananas [Musa sp. $(-0.335)]$ (Huang, 2005).

In the study by Carman and Cook (1996), the price flexibility of demand for California avocados is -1.53 , which means the demand for U.S. 'Hass' avocados is inelastic. From a marketing perspective, this indicates that 'Hass' avocado prices are very responsive to changes in quantity, which is the opposite for Florida green-skin avocados. It is important to point out that effective advertising and promotional campaigns have increased the demand for 'Hass' avocados. In contrast, there 
Table 2. Scenarios reflecting the potential changes in prices as a consequence of a $10 \%, 30 \%, 40 \%$, and $50 \%$ reduction in supply of Florida green-skin avocados due to the outbreak of laurel wilt disease (e.g., a $10 \%$ reduction in the quantity of Florida avocado supply which is equivalent to $\approx 113,818$ bushels is likely to cause the price of avocados to increase from base price of $\$ 21.56$ to $\$ 22.74$ representing a difference of $\$ 1.18$ ).

\begin{tabular}{|c|c|c|c|c|c|}
\hline Scenario & $\begin{array}{c}\text { Change in quantity } \\
\text { supplied (\%) }\end{array}$ & $\begin{array}{c}\text { Reduction in } \\
\text { supply (bushels) }\end{array}$ & Old price $(\$ / \text { bushel })^{\mathrm{z}}$ & New price $(\$ /$ bushel $)$ & Difference $(\$)$ \\
\hline 1 & 10 & 113,818 & 21.56 & 22.74 & +1.18 \\
\hline 2 & 30 & 341,455 & 21.56 & 25.12 & +3.56 \\
\hline 3 & 40 & 455,273 & 21.56 & 26.31 & +4.75 \\
\hline 4 & 50 & 569,091 & 21.56 & 27.50 & +5.94 \\
\hline
\end{tabular}

${ }^{\mathrm{z}} 155-\mathrm{lb}$ bushel $=24.9476 \mathrm{~kg}, \$ 1 / \mathrm{bushel}=\$ 0.0182 / \mathrm{lb}=\$ 0.0401 / \mathrm{kg}$.

have been no advertising and promotional campaigns to increase the demand for Florida green-skin avocados.

The results of our analysis have several implications for the industry in light of recent developments within the industry. As mentioned earlier, laurel wilt disease has caused a $1 \%$ decline in output. If a cost-effective treatment is not discovered soon, further losses can be expected. Table 2 summarizes the likely short-term impact on the prices Florida growers would receive, assuming damage from the disease, if Florida crop output were to fall by $10 \%$ to $50 \%$ (Evans et al., 2010) of the 3-year average output level of $1,138,182$ bushels $(31,300$ tons $)$ given the 3 -year average price of \$21.56/bushel (USDAERS, 2014b). The information in Table 2 indicates that price would not rise substantially relative to the decline in output, as even in the worst-case situation of a $50 \%$ reduction in production, the price would increase by $\approx 27.5 \%$, or from $\$ 21.56$ to $\$ 27.50$ per bushel. The implication is that although green-skin avocado can be considered a niche market, there is a limit to how much consumers would be willing to pay for the commodity. The result seems plausible, especially in light of the fact that avocados like many other tropical fruits are not considered staples, and so there is a limit to the amount that consumers are willing to spend on these commodities.

Moreover, in the longer run, when prices have begun to adjust upward, it is not unforeseeable that imports from the DR would increase to take up the slack. Although the production seasons of the two countries do not overlap perfectly, there is sufficient overlap to enable the DR to ramp up its exports to the United States, filling the gap and exerting downward pressure on prices. At the moment, it is fairly well understood that the main barrier to further increases in U.S. imports from the DR. is due to relatively low prices for avocado, which makes it less attractive during the peak of the Florida production season. Any upward movement of prices would provide the price incentive needed to facilitate trade. Further modeling using some of the parameters uncovered in this study would be needed to provide greater insight of the longer-term implications that could arise in such a situation.

\section{Summary and conclusions}

This article uses an inverse demand model for green-skin avocados in the United States to shed light on the possible price effects resulting from changes in the supply of green-skin avocados due to recent developments in the industry. The estimated price flexibility of -0.551 evaluated at the mean indicates that Florida avocado prices are not very responsive to changes in the quantity supplied. A $10 \%$ reduction in the quantity supplied is likely to result in a less than proportionate (only $5.5 \%$ ) increase in prices. Hence, the increase in prices resulting from a reduction in the availability of green-skin avocados due to the spread of laurel wilt disease may be insufficient to adequately compensate growers for additional management costs incurred due to the disease. At the same time, the rise in price may be sufficient to provide the additional incentive needed by the DR to further penetrate the U.S. green-skin avocado market.

DR exports do not have a significant effect on the wholesale price for Florida green-skin avocados despite the substitution relationship between domestic and imported avocados.
This may be explained by the fact that imported avocados arrive in the United States at a time when local supplies are not at their peak so that DR exporters can minimize competition and maximize their margins. The DR may widen the window of opportunity to take advantage of any shortfalls that result of disease outbreaks in the Florida production areas.

In contrast to supplies from the DR, our results suggest that the quantity of 'Hass' avocados on the market has a significant effect on the price for Florida green-skin avocados; findings indicate that increases in the total supply of 'Hass' avocados exert a downward pressure on the price for Florida green-skin avocados. Although green-skin avocados are considered a niche market, there appears to be a level of substitution at the fringes due partly to the successful promotional campaign by the Hass Avocado Board (2014).

In general, our study suggests that even though disease represents a real threat to the Florida green-skin avocado industry, prices will not rise substantially in the future due to the tempering effect of green-skin avocado exports from the DR and the increased availability of 'Hass' avocados.

\section{Literature cited}

American Institute of Cancer Research. 2013. AICR health talk. 5 May 2015. <http:// www.aicr.org/press/health-features/healthtalk/2013/09sept2013/DifferencesBetween-Types-of-Avocados.html .

California Avocado Commission. 2014. Selling: Pounds and dollars by variety. 5 May 2015 . <http://www. californiaavocadogrowers.com/selling/ pounds-and-dollars-variety>.

Carman, H.F. and R. Cook. 1996. An assessment of potential economic impacts of 
Mexican avocado imports on the California industry. Acta Hort. 429:227-234.

Carman, H.F. and R.K. Craft. 1998. An economic Evaluation of California Avocado Industry Marketing Program, 1961-1995. 5 May 2015. <http://giannini.ucop.edu/ ResearchReports/345-Avocado.pdf $>$.

Carman, H.F. and R.D. Green. 1993. Commodity supply response to a producer-financed advertising program: The California avocado industry. Agribusiness 9(6):605-621.

Crane, J.H., C.F. Balerdi, and I. Maguire. 2013. Avocado growing in the Florida landscape. 5 May 2015. <http://edis.ifas. ufl.edu/pdffiles/MG/MG21300.pdf>.

Di Giacomo, M. 2008. GMM estimation of a structural demand model for yogurt and the effects of the introduction of new brands. Empir. Econ. 34(3):537-565.

Dominican Republic Ministry of Agriculture. 2014. Estadisticas. 5 May 2015. <http:// www.agricultura.gob.do/estadisticas/siembracosecha-y-produccion-agropecuaria/ $>$.

Evans, E., J. Crane, A. Hodges, and J. Osborne. 2010. Potential economic impact of laurel wilt disease on the Florida avocado industry. HortTechology 20:234238.

Evans, E. and I.B. Lozano. 2014. Sample Avocado Production Costs and Profitability Analysis for Florida. 5 May 2015. <http:// edis.ifas.ufl.edu/fe837>.

Food and Agriculture Organization of the United Nations. 2014. Crops: Production. 5 May 2015. <http://fasostat.fao.org/ site $/ 567 /$ default.aspx\#ancor $>$.

Florida Department of Agriculture and Consumer Services. 2013. Florida Agriculture by the Numbers, 2013 Statistical Directory. 5 May 2015. <http://freshfromflorida. s3.amazonaws.com/Media\%2FFiles\% 2FMarketing-Development-Files\%2FAg_stats_ 2013_with+covers.pdfP-01304.pdf>.

Hass Avocado Board. 2014. Retail Sales Opportunity Analysis: Distribution and Sales of Green-Skin and Hass Avocados. 5 May 2015. <http:// www.hassavocadoboard.com/retail/retailsales-opportunity-analysis-greenskin>.

Huang, K.S. 2005. How Reliable Is It to Obtain Price Flexibilities from Inverting Price Elasticities. 5 May 2014. <http:// ageconsearch.umn.edu/bitstream/ 19335/1/sp05hu09.pdf>.

Lee, M.Y.A. and E.M. Thunberg. 2013. An inverse demand system for New England groundfish: Welfare analysis of the transition to catch share management. Amer. J. Agr. Econ. 95(5):1178-1195.

Lundberg, J. and S. Lundberg. 2012. Distributional effects of lower food prices in a rich country. J. Consum. Policy 35 (3):373-391.

Park, H. and W.N. Thurman. 1999. On interpreting inverse demand systems: A primal comparison of scale flexibilities and income elasticities. Amer. J. Agr. Econ. 81 (4):950-958.

Thurman, W.N. 1987. The poultry market: Demand stability and industry structure. Amer. J. Agr. Econ. 69(1):30-37.

U.S. Bureau of Economic Analysis. 2014. GDP \& personal income. 5 May 2015. <http://www.bea.gov/iTable/ index_nipa.cfm>.
U.S. Bureau of Labor Statistics. 2014. Producer price index. 5 May 2015. $<$ http://www.bls.gov/ppi>.

U.S. Department of Agriculture, Agricultural Marketing Service. 2014a. Fruit and Vegetable Market News: Custom Report: Movement. 5 May 2015. <http://www.marketnews.usda.gov/ portal $/ \mathrm{fv}>$.

U.S. Department of Agriculture, Agricultural Marketing Service. 2014b. Fruit and Vegetable Market News: Custom Report: Terminal Market. 5 May 2015. <http://www.marketnews.usda.gov/ portal $/ \mathrm{fv}>$.

U.S. Department of Agriculture, Economic Research Service. 2014a. Yearbook Tables. Supply and Utilization: Table G-3. 5 May 2015. <http://www.ers.usda.gov/ datafiles/FruitTreeNuts_YearbookTables/ Supply_and_Utilization/Table-G3.xlsx > .

U.S. Department of Agriculture, Economic Research Service. 2014b. Yearbook Tables. Noncitrus Fruit: Table B-9. 5 May 2015. <http://www.ers.usda.gov/datafiles/ FruitTreeNuts_YearbookTables / Noncitrus_fruit/Table-B9.xlsx>.

U.S. Department of Agriculture, Foreign Agricultural Service. 2014. Global Agricultural Trade System: Standard Query. 5 May 2015. <http://apps.fas.usda.gov/ gats/ExpressQueryl .aspx>

U.S. Department of Agriculture, National Agricultural Statistics Service. 2014. Census of Agriculture. Chapter 1: State Level Data. 5 May 2015. <http://www.agcensus.usda. gov/Publications/2012/Full_Report/ Volume_1,_Chapter_1_State_Level/ Florida/>. 